\title{
EL USO DE LA HERMENÉUTICA ANALÓGICA EN LOS DERECHOS HUMANOS. CASO DE LA PROPIEDAD INTELECTUAL VS PROCOMÚN
}

\author{
The use of analogical hermeneutics in human rights. Case intellectual \\ property vs pro-common
}

Edgar Alejandro MARTÍNEZ VARGAS

\begin{abstract}
Sumario:
I. Introducción. II. La ciencia hermenéutica. III. La hermenéutica analógica. IV La hermenéutica en el derecho. V. La hermenéutica analógica en el derecho: VI. La hermenéutica analógica en los derecho humanos. VII. La universalidad frente a la particularidad de los derechos humanos. VIII. Perspectivas universalistas positivistas se imponen a las diferencias. IX. Disputa entre las posturas univocistas y relativistas en el conocimiento. Propiedad intelectual vs procomún. X. Hermenéutica analógica para la mediación entre la propiedad intelectual y el procomún. XI.Conclusiones. XII. Referencias.
\end{abstract}

Resumen: La propuesta de una hermenéutica analógica, respaldada en la equidad y prudencia, permite el dialogo entre posturas teóricas antagónicas que a primera vista parecen inconciliables. Es de esta manera que se establece la posibilidad de un intercambio de opiniones para llegar solución que satisfaga a partes contrarias. Tal situación se muestra al aplicarla en los derechos humanos en sus posturas positivistas normativas y alternativas al derecho. Para ello se toma el caso de la propiedad del conocimiento.

Palabras clave: Hermenéutica analógica. Dialogo. Intercambio. Derechos Humanos. Positivistas. Alternativas. Propiedad del conocimiento.

Abstract: The proposal for an analogical hermeneutics, backed by equity and prudence, allows for a dialogue between opposing theoretical positions that at first sight seem irreconcilable. It is in this way that the possibility of an exchange of views is established in order to reach a solution that satisfies to opposing parties. Said resolution is shown when is applied in human rights perspectives in the positivism normativity and alternatives to the law. For this, it takes the case of the ownership of knowledge.

Keywords: Analogical hermeneutics. Dialogue. Exchange. Human rights. Positivism Alternatives to law. Ownership of knowledge.

\section{INTRODUCCIÓN}

En este trabajo se realiza un breve recorrido de la ciencia hermenéutica, así como de los conflictos entre las interpretaciones universalistas y las relativistas existentes en la realidad. Para ello se hace referencia a autores clásicos de cada una de las corrientes que dan sentido a

\footnotetext{
${ }^{1}$ Licenciado en Derecho por la Universidad de Guanajuato y actualmente alumno de la Maestría en Derechos Humanos de la Universidad Autónoma de San Luis Potosí.
} 
dicha ciencia. Finalmente, se toma a la perspectiva de interpretación propuesta por Mauricio Beuchot para dar un sentido de armonía a estas teorías interpretativas y a sus discusiones teóricas que influyen en el derecho.

En un segundo momento, se traslada dicha discusión al ámbito de los derechos humanos concluyendo en el conflicto entre leyes positivas y perspectivas alternativas del derecho. Es a partir esta situación que se realiza un ensayo de análisis entre perspectivas universalistas, así como de las relativistas en relación al derecho de la propiedad intelectual. Dicho análisis se propone en concordancia de los elementos que se le atribuyen a la analogía para lograr conciliar las propuestas que son contrarias, debido a las pretensiones que defiende cada una de ellas. Lo anterior se realiza de manera sencilla y planteando realizar una propuesta de solución al conflicto existente entre la propiedad del conocimiento y una propiedad común del conocimiento para la humanidad o procomún. Por último, se presentan las posibles circunstancias en las cuales ambas perspectivas podrían coexistir manteniendo un principio rector de objetividad a partir del uso de la hermenéutica analógica.

\section{LA CIENCIA HERMENÉUTICA}

Es necesario en un primer momento definir a la herramienta que se pretende utilizar antes de entrar directo a la discusión de los derechos humanos y de la propiedad intelectual desde la perspectiva hermenéutica. Además de hacer algunas aclaraciones teóricas en el transcurso del texto relacionadas con el uso de la hermenéutica en el derecho, en los derechos humanos, así como su uso filosófico-jurídico en la discusión de las perspectivas univocistas y equivocistas para contextualizar la problemática.

La primera aclaración se refiere a la hermenéutica como concepto, la cual ha tenido varios sentidos y ha sido utilizada de diferentes maneras en el transcurso del tiempo. Su origen proviene del verbo griego hermeneuin que hace referencia al proceso de interpretar o de traducir en términos generales, sin referirse a un proceso en específico. Es así que en épocas antiguas fue utilizada y entendida solo como una técnica de interpretación, sin embargo, con el tiempo y con la evolución filosófica se rescató como una ciencia de la interpretación. ${ }^{2}$ Así, en la actualidad va más allá de la simple apreciación de los textos ya que se torna a la vez comprensiva y crítica de su mismo estudio. ${ }^{3}$

En este sentido, Mauricio Beuchot la percibe con un doble uso o dos formas de actuar. Por un lado, es una ciencia y por el otro, es un arte. Es considerada como una ciencia ya que es el resultado de un conjunto ordenado de conocimientos. Y es un arte en un perfil de técnica porque contiene un procedimiento para la realización de una actividad. ${ }^{4}$ Entonces, siguiendo estas especificaciones se presenta como una ciencia de la interpretación de los textos para lograr una comprensión crítica de los mismo, pero que mantiene un procedimiento que le permite allegarse de la información final con que se va a sintetizar. Sería, pues, un proceso de profundización de un texto. ${ }^{5}$ Aunque Gadamer amplía la interpretación hacia el texto hablado, o mejor dicho, hacia las expresiones orales de las personas. Por lo tanto,

\footnotetext{
${ }^{2}$ BUGANZA Torio, Jacobo, Consideraciones sobre la hermenéutica analógica de Mauricio Beuchot, Hermenéutica analógica, derecho y filosofía, San Luis Potosí, UASLP, 2007, p.9.

${ }^{3}$ BEUCHOT, Mauricio, Hermenéutica analógica, analogía y derechos humanos, San Luis Potosí, CEJSM/ UASLP, 2010, p 23.

${ }^{4}$ BUGANZA Torio, Jacobo, Op. Cit., nota 2, p 11.

${ }^{5}$ BEUCHOT, Mauricio, Op. Cit., nota 3, p. 12. 
la perspectiva de la interpretación queda abierta no sólo hacía unas personas expertas de la hermenéutica, sino que cualquier persona queda inmiscuida en la actividad interpretativa convirtiéndonos a todo/as en hermeneutas. Sin embargo, lo relevante de estas expresiones humanas, la escrita o la oral, es que todas contienen un material que se puede interpretar por medio de la hermenéutica.

Ahora bien, para lograr entablar la interpretación son necesarios los siguientes elementos: el sujeto que genera el mensaje, el medio por el cual se transmite y el lector o receptor que va a interpretar aquello emitido. ${ }^{6}$ De la relación de los tres, es decir, de las dinámicas entre ellos surge la comprensión, la cual se presenta en diversos sentidos. ${ }^{7}$ El primero de ellos se apega a la intención de quien emite el mensaje partiendo de que busca transmitir una idea que debe de llegar finalmente al destinatario del mismo (receptor/a). En caso de que se lograr este tipo de vínculo la interpretación se consideraría como una hermenéutica que se inclina por la objetividad. En segundo lugar, tendremos una situación opuesta a la anterior, en la cual el receptor/a interpreta desde su particularidad el mensaje propuesto por el autor/a. De esta manera, se manifiesta una comprensión subjetiva partiendo de las peculiaridades de quien recibe el mensaje. Dejando, finalmente, de lado la intención que pudiera tener el mensaje emitido en un principio.

La interpretación, pues, independientemente como se realice tendrá que ser objetiva o subjetiva de acuerdo de si se apega al creador del mensaje o bien a la subjetividad del receptor. No obstante, además de estas circunstancias el mensaje y la dinámica de transmisión puede ser influido con una serie de prejuicios o preconceptos que se tienen culturalmente y que se considera como parte de las personas. Los mensajes se ven afectados por la experiencia de vida del creador/a o del receptor/a de los mismos. A esta carga Heidegger la nombró como el problema hermenéutico por el cual el proceso de comprensión se inicia de un preconocimiento que influye a la hora de entablar una interpretación. ${ }^{8}$ Sin embargo, Gadamer afirma que estos prejuicios o pre-conocimientos no tienen porqué interferir con nuestras interpretaciones, ya que aun teniéndolos, las personas poseen la capacidad intelectual para superarlos en búsqueda de la misma objetividad. ${ }^{9}$

Retomando lo antes expuesto, la interpretación solo parece darse de forma objetiva apegándose a la voluntad de quien las crea, en otras palabras, al disolver los bordes de la interpretación individual se debería destacar la perspectiva objetiva del mensaje. ${ }^{10}$ Sin embargo, esta forma de interpretación se convierte en un ideal de obediencia al texto o mensaje ya que para lograr apegarse a lo que dicta es indispensable una auto-interpretación. A saber, para un adecuado empleo de la hermenéutica es indispensable realizar una auto-inspección del cómo se llevará a cabo la realización de lo que dice el texto. Pero además se necesita de una crítica constructiva del porqué llevarlo de esa manera y no de otra que sea diversa a la propuesta. Esto será lo que Mauricio Beuchot describe en el derecho como un aplicación de la interpretación de la ley al caso concreto. ${ }^{11}$ Por otra parte, la interpretación subjetiva corre

\footnotetext{
${ }^{6}$ Ídem.

${ }^{7}$ La comprensión entendida en este contexto, como un concepto.

${ }^{8}$ Ídem.

${ }^{9}$ GADAMER, Hans Georg, Fundamentos de una hermenéutica: verdad y método, Ana Agud Aparicio y Rafael de Agapito (Trads.), Salamanca, SIGUEME, 1993, p. 142.

${ }^{10}$ BEUCHOT, Mauricio, Op. Cit., nota 3, p. 13.

${ }^{11}$ Ibídem, p. 17.
} 
el riesgo de perderse en el relativismo ya que no cuenta con un punto objetivo como eje de realidad, circunstancia que se analizan más adelante.

En resumen, la interpretación hermenéutica se encuentra en dos sentido, la objetiva y la subjetiva. Cada una de ellas se resolverán atendiendo al contexto en que se presenten. Para lograr dar una salida a esta situación se propone la alternativa de la analogía. Es precisamente con ésta que Mauricio Beuchot sugiere la posibilidad de mantener cierta objetividad atendiendo a las subjetividades, pero todo esto sin llegar a los extremos, en otras palabras, manteniendo una perspectiva justa de ambas posturas. La alternativa propuesta es la conocida como la hermenéutica analógica.

\section{LA HERMENÉUTICA ANALÓGICA}

En la hermenéutica analógica la principal característica, tal y como lo expresa su nombre, es la analogía. La idea o propuesta analógica proviene de teorías clásicas que promovían la utilización de este tipo de concepto. En primer momento, Hans-Georg Gadamer la utilizó a partir del concepto de la phrónesis o prudencia utilizados en los trabajos de los filósofos griegos clásicos como Platón y Aristóteles. En esta lógica, el concepto tiene relación directa con un sentido o un ser ético. Es decir, un ser continuó que ayuda a distinguir entre lo conveniente y lo no conveniente que conlleva una distinción permanente en lo que se puede considerar como lo bueno o lo malo. ${ }^{12}$ Entonces, la phrónesis puede entenderse como un concepto que en griego equivaldría a la analogía. ${ }^{13}$

Partiendo de lo anterior, la analogía termina por ser ese procedimiento por medio del cual se puede distinguir entre dos supuestos contrarios. Para ello se toma en consideración un diálogo que ayuda a establecer atribuciones de un sentido y del otro, aun siendo opuestos. Es así que a través de la analogía se logra establecer una armonía o mejor dicho un entendimiento entre la objetividad y la subjetividad, entre lo universal y lo particular, entre lo unívoco y equívoco. En este sentido, no hay necesidad de renunciar a toda universalidad para lograr salvaguardar las particularidades, ni es necesario sacrificar la particularidad para asegurar aquello que es universal u objetivo. ${ }^{14}$

Por lo tanto, una hermenéutica basada en la analogía es aquella, con la cual se busca una interpretación que no pretende una objetividad ni el rigor que ella supondría. La objetividad no es su finalidad ya que con ella se estaría en frente de una promesa inalcanzable. En este mismo sentido, la interpretación analógica tampoco esperaría llegar a lo equívoco ya que en ella se perdería todo idea de objetividad. En consecuencia, se presume que la hermenéutica analógica se coloca en una situación de mediación y por lo tanto en busca de un justo medio.

La justificación de la postura de la hermenéutica analógica es la existencia de propuestas univocistas y de las equivocistas en la vida cotidiana. La primeras basadas en una sola interpretación posible y rígida, o sea, la verdadera, la objetiva o la universal. Éstas regularmente se encuentran respaldados en la ciencia, es decir, se muestran como lo racional y de ahí se toma su fundamento para considerarse como legítimo y sin posibilidad de un diálogo. Las equivocistas, basadas en la subjetividad en extremo, permitiendo obviar a lo semejante y

\footnotetext{
${ }^{12}$ GADAMER, Hans Georg, Op. Cit., nota 9, p. 51-52.

${ }^{13}$ BEUCHOT, Mauricio, Op. Cit., nota 3, p. 14.

14 BEUCHOT, Mauricio, "Hermenéutica analógica, derechos humanos y culturas", Problemas contemporáneos de la filosofía del derecho, México, UNAM, 2005, p. 55.
} 
resaltando la diferencia. Así, la diversidad de propuestas acaba por perder las proposiciones en la inconmensurabilidad de opciones posibles y válidas.

En síntesis, la propuesta de la hermenéutica analógica es mantenerse cerca de las interpretaciones universales y racionales, pero lo suficientemente abiertas al diálogo para dejar la oportunidad de plantear nuevas perspectivas y puntos de vista que enriquezcan a las interpretaciones. Así, es posible mantenerse en proporción en las exigencias que puedan presentarse más allá de lo racional dando humildad para reconocer que no es posible alcanzar totalmente la intención del autor y da la libertad y el empuje para ir fuera de la tradición misma del autor. ${ }^{15}$

\section{LA HERMENÉUTICA EN EL DERECHO}

El uso de la interpretación hermenéutica en el derecho es común. Se encuentra presente debido a la necesidad de dar sentido a la normas que se consideran no claras o en aquellos casos en que existen vacíos legales. Es útil para la aplicación de la ley al caso concreto. Sin embargo, al igual que en otros lugares se encuentra con el peligro de las interpretaciones univocistas o equivocistas. ${ }^{16}$ Para ello, se muestra de manera rápida las expresiones de cada una con el fin de contextualizar la problemática. En primer lugar, la perspectiva univocista se encuentra en las interpretaciones de autores como Betti que se basaron en un monismo metodológico que nutrió al movimiento positivista del siglo XIX y que se encontraba muy apegado a las explicaciones del mundo natural.

Con base en este tipo de teoría se llegó a una teoría general de la interpretación con lo que se dio inicio a un interpretación conocida como stricto sensu. La finalidad es comprender la objetividad, dentro de la ciencia jurídica. ${ }^{17}$ Terminando en una propuesta inalcanzable del derecho como un ideal de la interpretación del sentido real que tiene el texto de la ley. En fin, convirtiéndose solamente en un modelo regulativo de la comprensión del derecho. ${ }^{18}$

Por otra parte, encontramos la propuesta de Hans-Georg Gadamer con la que se realza la interpretación del conocimiento. Su propuesta es una hermenéutica relativista basada en la historicidad y la subjetividad de los intérpretes llegando incluso a considerarse de corte escéptico. En esta hermenéutica cada individuo interpreta al mundo, ya que ésta es una característica natural del ser humano, por lo tanto es considerado por algunos autores dentro de las interpretaciones relativistas. Sin embargo, las verdaderas teorías equivocistas de la interpretación se encuentran en las escuelas jurídicas pos-modernas representadas por Douzinas y Warrington.

\section{LA HERMENÉUTICA ANALÓGICA EN EL DERECHO}

El uso de la interpretación analógica en el derecho, al igual que en otras áreas, tiene una finalidad de mediación entre las diferentes teorías universales y relativistas existentes en la interpretación. Pero, en este caso no solamente de las normas jurídicas, sino en el uso de esta

\footnotetext{
${ }^{15}$ BEUCHOT, Mauricio, La hermenéutica en la edad media, citado en Jacobo, Buganza Torio, "Consideraciones sobre la hermenéutica analógica de Mauricio Beuchot”, Hermenéutica analógica, derecho y filosofía, San Luis Potosí, UASLP, 2007, p.19.

${ }^{16}$ BEUCHOT, Mauricio, Op. Cit., nota 5, p. 16.

${ }^{17}$ TRUJILLO, Isabel, "El poder de la razón jurídica: nota sobre el desarrollo de la hermenéutica jurídica italiana", Cuadernos de filosofía del derecho, Doxa, núm. 27, 2004, p. 441. [edición dígital]

${ }^{18}$ BEUCHOT, Mauricio, Op. Cit., nota 3, p. 16.
} 
area del conocimiento como herramienta argumentativa. En este sentido, se propone basarse en este tipo de hermenéutica para encontrar la intención del legislador sin llegar a una completa objetividad, quedando abierta a una discusión válida de otras opiniones críticas. Aunque cuidando encontrarse cerca de las opiniones que se consideran objetivas para lograr la justicia. De esta manera, y con la finalidad de obtener una postura apegada a la objetiva la hermenéutica analógica se basa en un procedimiento que parte de límites y de jerarquías para la interpretación.

Dichas jerarquías y límites impuestas en la hermenéutica analógica son elementos que sirven para nivelar las interpretaciones analógicas y no llegar al relativismo o a lo universal. En otras palabras, estos conceptos son utilizados para lograr establecer un punto objetivo que mantenga un norte teórico, que en el caso del derecho sería la justicia. Para conquistar este objetivo se enfoca un diálogo entre ambas interpretaciones. En primer lugar, se encuentra el concepto de límite en referencia a considerar que no todas las interpretaciones que se generen de una cuestión pueden ser válidas. La razón de los límites es mantener el diálogo presente entre las interpretaciones, que mantienen la posibilidad de nutrirse de las perspectivas diversas. Es así que se logra un equilibrio entre el conocer y la percepción. ${ }^{19}$ Por otra parte, se localiza la jerarquía que se encuentra relacionada de manera directa con los límites. Su función es la de ordenar las interpretaciones desde las más válidas hasta las menos válidas. De esta forma existen interpretaciones que contienen un cierto grado de certeza, por lo que se van ordenando de acuerdo su cercanía con la verdad o la objetividad y en el caso del derecho con la justicia.

No obstante, estos dos elementos no son lo únicos que utiliza la hermenéutica analógica para llegar a la objetividad. Además, tiene un sustento teórico del concepto de ícono de Pierce y su hermenéutica metafórica. ${ }^{20}$ En este sentido, la iconicidad, entendida a partir del signo icónico se utiliza como la intermediación de lo natural y lo cultural, adecuandolo en la analogía como aquello que media entre lo unívoco y lo equívoco transformándose en una interpretación analógica-icónica. ${ }^{21}$ De esta manera, una interpretación analógica del derecho parte de los 'límites' tanto en la univocidad, que no es alcanzable, como el la equivocidad, que tiende a perderse. Colocando de esta manera el justo medio de ambas y así se vuelve un medio para alcanzar la justicia. ${ }^{22}$

Otro de los elementos en que se apoya la hermenéutica analógica, y que proviene de la phrónesis, es la epeiqueia que se entendería como una aplicación adecuada de la ley. Incluso puede variar en una inobservancia de la misma norma cuando el intérprete considera que esta ley va en contra del principio de justicia o de la equidad natural, o sea, que aplicar la ley en varias circunstancia sería injusto. ${ }^{23}$ Así pues, el uso de la equidad se vuelve en una forma de justicia que tiene un origen más allá de la norma positivista y racional del derecho moderno. La finalidad de la equidad se funda en la posibilidad de brindar una solución que beneficie a cada una de las partes que se encuentran en un conflicto, en el cual la ley se tiene que interpretar para dar una solución al caso concreto. Para ello es indispensable la presencia de

\footnotetext{
${ }^{19}$ BUGANZA TORIO, Jacobo, Op. Cit., nota 2, p. 24.

${ }^{20}$ BEUCHOT, Mauricio, La hermenéutica como herramienta en la investigación social, San Luis Potosí, CEDHSLP/UASLP, 2007, p. 11.

${ }^{21}$ BEUCHOT, Mauricio, Op. Cit., nota 3, p. 28.

${ }^{22}$ Ídem.

${ }^{23}$ SUÁREZ, Francisco, Tratado de las leyes y de Dios legislador, citado en Jesús Antonio de la Torre Rangel, El derecho como arma de liberación en América Latina: sociología y uso alternativo del derecho, San Luis Potosí, CENEJUS/UASLP, 2006, p.165.
} 
una sutileza por parte del intérprete de la norma que se va aplicar permitiendo la posibilidad de una prudencia jurídica en el derecho. ${ }^{24}$

Dicha prudencia jurídica permite apreciar una relación cercana entre la ética y el derecho, aunque es común encontrar una separación entre ambos desde una perspectiva dogmática de las visiones univocistas. Sin embargo, desde un horizonte iusfilosófico la no-relación entre la ética y el derecho puede concluir en un derecho que no busque la justicia como tal, sino sólo la legalidad. En este panorama se pierde el objetivo del bien común, terminando en la satisfacción de intereses de los más poderosos, dejando en un estado de desventaja a los pobres de la sociedad. ${ }^{25}$

\section{LA HERMENÉUTICA ANALÓGICA EN LOS DERECHOS HUMANOS}

La aplicación de la hermenéutica analógica en los derechos humanos tiene como principal función la mediación de la polémica entre las posturas universalista y las particulares que influyen en el ejercicio de los mismos. Dicha polémica surge principalmente entre las interpretaciones del multi-culturalismo y una percepción objetiva o universalista y eurocéntrica de los derechos humanos. Siendo una herramienta útil para el entendimiento de los derechos humanos positivizados en ley y tratados internacionales con respecto a el ejercicio de los derechos por parte de las mayorías populares, que se manifiestan principalmente a través de los movimientos sociales.

En este sentido, es necesario partir de que existen varias interpretaciones de lo que son los derechos humanos, así como el fundamento que les da sentido. Por ello, de manera breve ya que debido al tiempo y la extensión del artículo no es posible extender más la discusión se hace una referencia rápida de las dos posturas contradictorias. En primer lugar, se encuentra el entendimiento de los derechos humanos surgidos después de la segunda guerra mundial positivizados en tratados internacionales y respaldados por organismos internacionales como la Organización de las Naciones Unidas. En esta perspectiva el fundamento de los derechos humanos se encuentra en la dignidad humana en la cual el simple hecho de ser humanos nos brinda la capacidad de ser sujetos de derechos.

Por otra parte, se encuentra la postura crítica, en la cual los derechos humanos surgen de las luchas populares. En esta lógica, su fundamento no se encuentra en la dignidad de la persona, o no solamente en esta idea. Por lo tanto, lo que les da sentido son las necesidades humanas y la manera en que se busca satisfacerlas. Es así que su ejercicio se relaciona directamente con la satisfacción de las necesidades de cada persona y por lo tanto no existe una postura universal y tampoco una sola manera de entenderlos y ejercerlos. Entonces, es necesario partir de las circunstancias particulares de cada situación, así como de la geopolítica o corpo-política de la población para ampliar la visión de su ejercicio. ${ }^{26}$

Una vez expuesto lo anterior, se puede plantear que los derechos humanos en la actualidad tienden a una postura univocista y en un sólo sentido, el cual es conocido como el oficial y positivizado en leyes y tratados internacionales. Por lo que las posturas críticas

\footnotetext{
${ }^{24}$ MASSIANI C.I., "La interpretación jurídica como interpretación práctica” citado en Mauricio Beuchot, Hermenéutica analógica, analogía y derechos humanos, San Luis Potosí, CEJSM/UASLP, 2010, p 29.

${ }^{25}$ Pobres se utiliza como lo entiende Jesús Antonio de la Torre Rangel, desde un sentido sociológico. Pobres respecto a falta de derechos, es decir, pobres en derechos. En Jesús Antonio de la Torre Rangel, op. Cit. p.178.

${ }^{26}$ ELLACURÍA, Ignacio, "Historización de los derechos humanos desde los pueblos oprimidos y las mayorías populares”, en Juan Antonio Senent (ed.) La lucha por la justicia. Selección de textos de Ignacio Ellacuría 1969-1989, Bilbao, Universidad de Deusto, 2012, p. 365.
} 
cuestionan esta tendencia de universalización, fundamentando que los derechos humanos deben partir desde la realidad y la propia experiencia de quienes sufren la negación de sus derechos. ${ }^{27}$ Es por ello que se propone el uso de la hermenéutica analógica para conseguir la mediación necesaria entre las posturas.

De esta manera, se establece un diálogo desde el cual, cada una de las visiones propone y plantea sus perspectivas, en una suerte de dialéctica. Pero una dialéctica no hegeliana ya que en ella no se espera la llegada de una síntesis de ambas posturas en la que se concilie de una manera total a los contrarios. ${ }^{28}$ Por consiguiente, la expectativa del uso de la analogía en los derechos humanos es una coincidencia simple con la cual se espera una conciliación apenas con fuerza para que convivan ambas posturas, pero que este no cambie sus características antitéticas. ${ }^{29}$ Así pues, se mantiene las esencias de ambas perspectivas de derechos, pero se mantiene una armonía con la cual pueden coexistir las personas, aunque no estén completamente de acuerdo con las ideas contrarias, llegan a aceptar posturas diversas.

El uso de la interpretación analógica en los derechos humanos implica una separación de la ley. De tal forma que esta última se considera solamente como una guía, pero no es la única referencia que se tiene para aplicar un derecho. Así, se recurre al uso de los principios que se filtran en el entendimiento de las normas. Se pretende superar la separación del derecho y de la moral, es decir, ir más lejos de las perspectivas modernas del derecho y con ello de la modernidad que desconectó a la ética del derecho para establecer una coherencia moral de su utilización. ${ }^{30}$ En este sentido, el derecho se percibe con el eje rector de los principios supremos del derecho que se reflejan en los valores más importantes para el ser humanos, como la dignidad, la libertad, la igualdad, entre otros. Es así que los principios sirven como guía para las interpretaciones, o sea, son utilizados para no alejarse del objetivo que tendrían los derechos humanos el cual sería mantenerse en beneficio de las mayorías populares. ${ }^{31}$

\section{LA UNIVERSALIDAD FRENTE A LA PARTICULARIDAD DE LOS DERECHOS HUMANOS}

La principal dificultad existente entre las visiones universalistas y particulares de los derechos humanos, expuesta brevemente con anterioridad, se encuentran en la individualidad y lo comunitario del sentir de los derechos. El aspecto individualista de los derechos humanos proviene de la percepción eurocéntrica de los mismos que tiene su fundamento, en muchas de las ocasiones, en un iluminismo de la cultura liberal burguesa implantada en el positivismo jurídico. ${ }^{32}$ En tanto que desde el multiculturalismo los derechos se asimilan a una visión más comunitaria pensada como un todo regularmente desde los pueblos originarios, pero en comunidad también desde otros grupos que aún insertos dentro de la occidentalidad no concuerdan del todo con la propuestas universalistas positivistas.

La propuesta de la hermenéutica analógica es entablar el diálogo entre ambas interpretaciones buscando resaltar las diferencias de la multiculturalidad, para lograr librar la barrera del univocismo. Sin embargo, rebasar el límite de lo universal conlleva el obstáculo de la diferencia, así pues, esta interpretación no puede perderse en la infinidad de entendimientos

\footnotetext{
27 Ídem. [Concepto referido constantemente por Ignacio Ellacuría]

${ }^{28}$ BEUCHOT, Mauricio, Op. Cit., nota 3, p. 77.

29 Ídem.

${ }^{30}$ Ibídem, p. 31.

${ }^{31}$ ELLACURÍA, Ignacio, Op. Cit., nota 26, p. 365.

${ }^{32}$ DE LA TORRE RANGEl, Jesús Antonio, El derecho como arma de liberación en América Latina: sociología y uso alternativo del derecho, San Luis Potosí, CENEJUS/UASLP, 2006, p. 171.
} 
sobre lo que se manifiesta como un derecho humano. Es así que aunque se privilegia la diferencia se mantiene una relación directa con lo objetivo ya que se trata de principios primordiales para los seres humanos. Entonces, la limitación se presenta en que aun considerando las diferencia como punto de interpretación esta no se aleja demasiado de la propuesta universal de los derechos humanos. En este sentido, discrepa con otras hermenéuticas que proponen partir de la diferencia para construir otras propuestas, como lo es la hermenéutica diatópica que parte de los topois, o lo particular, para entablar un diálogo intercultural, pero sin considerar una posibilidad de objetividad como tal. ${ }^{33}$ En la hermenéutica analógica se lucha por salvaguardar la universalidad de los derechos a pesar de estirarlos para que se adapten a las diferentes culturas en las que se realicen. ${ }^{34}$

\section{PERSPECTIVAS UNIVERSALISTAS POSITIVISTAS SE IMPONEN A LAS DIFERENCIAS}

La propuestas de interpretación positivistas y racionales implantadas en las leyes positivas actuales se presentan como la perspectiva oficial de los derechos humanos. Es de esta manera que legitiman el uso del derecho, con todo y sanciones jurídicas, sobre cualquier otro entendimiento de los derechos. En consecuencia, los diversos grupos existentes quedan a la orilla de un derecho racional sin una posibilidad de diálogo. No obstante, el uso de la hermenéutica analógica permite ver la posibilidad de discusión, pero se necesita de una estrategia en conjunto para lograr superar las dificultades reales que coloca las visiones univocistas de los derechos humanos. Para ello se ha posibilitado a el uso del derecho alternativo, el cual puede ser usado desde la interpretación del mismo derecho ya positivizado. La conjunción del uso alternativo del derecho con la analogía abre el camino para que otros entendimientos lleguen a sugerir distintas opciones de defensa y ejercicio de los derechos humanos.

Las propuestas universales pretenden subsumir a la realidad social en normas positivas, con ello mantienen un estado de sometimiento de una clase dominante. No obstante, el uso analógico de la interpretación posibilita la crítica hacia las acotaciones legales hechas por los legisladores, y basadas en la imposición de los cánones burgueses, para lograr ver la realidad en forma general observando las prácticas discriminatorias e injustas del derecho oficial. ${ }^{35}$ Partiendo del cuestionamiento de la universalidad y sumando los elementos de la hermenéutica analógica se posibilitan las interpretaciones privilegiando la diferencia, aunque como ya se mencionó se mantiene la identidad de lo objetivo. Para lograr esta acción se necesita del uso de la prudencia y de la equidad evitando así los excesos en su uso o en la inobservancia de la ley.

\section{DISPUTA ENTRE POSTURAS UNIVOCISTAS Y RELATIVISTAS EN EL CONOCIMIENTO. PROPIEDAD INTELECTUAL VS PROCOMÚN}

La situación de conflicto entre visiones de los derechos humanos se puede observar de manera clara en la propiedad intelectual, aunque existen otros ejemplos de perspectivas contrarias en el ejercicio de los derechos, se utiliza éste por el auge de la sociedad del conocimiento, las tecnologías de la información (TICs), así como el modelo económico de producción

\footnotetext{
${ }^{33}$ Hermenéutica propuesta por Boaventura de Sousa Santos.

34 BEUCHOT, Mauricio, Op. Cit., nota 3, p. 76.

${ }^{35}$ GÓMEZ ROMERO, Luis, citado en Jesús Antonio de la Torre Rangel, El derecho como arma de liberación en América Latina: sociología y uso alternativo del derecho, CENEJUS/UASLP, 2006, p. 174.
} 
flexible predominante en la etapa actual de globalización económica. Así, pues, la propiedad intelectual al ser parte de una propuesta universal de los derechos humanos, aunque surgió en una situación apartada de ellos, terminó por formar parte de la misma lógica y por lo tanto de la misma protección y perspectiva. Este tipo de propiedad mantiene un uso protector que se fundamenta en la creencia de que los generadores de las obras, tanto intelectuales como industriales, lo hacen a partir de su propio intelecto. Es por ello que tienen derechos morales y patrimoniales de esas representaciones del intelecto humano.

Es dentro de esta lógica que se ha protegido desde poco más de mediados del siglo pasado a la propiedad intelectual desde los derechos humanos. Aunque, se argumenta que la protección de la propiedad intelectual es en busca de un beneficio común, al no apartarse de las visiones individualistas y económicas, lo cierto es que persiste una perspectiva individualista y univocista del uso de los derechos humanos en cuanto a este tipo de propiedad. A saber, el derecho de la propiedad intelectual no solo involucra el beneficio para un individuo, sino que al estar bajo una lógica de mercado, las producciones intelectuales generan ganancias monetarias para algunos sectores privilegiados de la sociedad.

Dicha visión entiende que las producciones intelectuales, y también las industriales, se crean a partir del conocimiento de una sola persona o grupo de ellas, sin tomar en cuenta que el conocimiento humano se ha generado colectivamente a través de la historia. En base a lo anterior expolian el conocimiento y lo presentan como descubrimientos originales e innovadores por los cuales es necesario pagar por su uso. ${ }^{36}$ Además, como ya se mencionó, esta práctica es protegida como un derecho humano siendo parte de la Declaración Universal de los Derechos Humanos. Es así que aunque plantea un beneficio general de la ciencia y de la tecnología, su uso se encuentra limitado por un carácter económico protegido por un derecho oficial representado por el estado moderno. ${ }^{37}$

Por otra parte, existen las propuestas relativistas que establecen la necesidad de una propiedad común o procomún basándose en la crítica al supuesto beneficio general que proponen las normas positivas de la propiedad intelectual. Las manifestaciones por parte de diferentes grupos, que van desde pueblos indígenas hasta el movimiento de software, para que se respete su derecho al uso y disfrute del producto cultural y común de la ciencia y de la tecnología son diversas. Esto permite un sin número de acciones en contra de las normas que protegen a la propiedad intelectual, por parte de aquellas personas que se ven agraviadas

\footnotetext{
${ }^{36}$ BUSANICHE, Beatriz, "Conceptos clave para comprender la problemática”, Libres de monopolios sobre el conocimiento y la vida, San José Costa Rica,Vía Libre-Fundación Heinrich Boll, 2007, p. 44

${ }^{37}$ Es necesario entender que los derechos de la propiedad intelectual entraron en los intereses económicos mundiales a finales del siglo pasado desde su inclusión en las Rondas de Uruguay en beneficio de grandes empresas transnacionales como la industria farmacéutica. Situación que originó el Acuerdo General sobre Aranceles y Comercio (GATT) y con el tiempo dio paso a la Organización Mundial del Comercio (OMC) y que finalizó en los Acuerdos sobre los Aspectos de los Derechos de la Propiedad Intelectual (ADPIC) [esto en relación a la propiedad intelectual]. Por lo tanto cuando se mencionan los derechos de la propiedad intelectual se da un sentido de propiedad intelectual y de propiedad industrial, por lo menos para el presente artículo, puesto que han sido estos los principales afectados por las dinámicas económicas de corte neoliberal. Finalmente, la referencia a esta clase de derechos se comprende a nivel mundial, además, de que se le da relevancia a la OMC como un organismo de producción jurídica fuera del Estado, pero que afecta económicamente a al interior de él y con ello a los derechos humanos. En suma, los derechos de la propiedad intelectual son ampliados más allá de una postura jurídica, es decir, se atienden desde un entendimiento complejo y crítico para no simplificarlos solamente al ámbito jurídico. Hernández Cervantes, Aleida, La producción jurídica de la globalización económica: notas de pluralidad jurídica transnacional, San Luis Potosí, CENEJUS Mispat/UASLP/UNAM, 2014, 101.
} 
en sus derechos humanos relacionados con el conocimientos. Un ejemplo de ello son los pueblos indígenas con la biopiratería, en la que las grandes farmacéuticas e incluso algunas universidades, se apropian de conocimientos ancestrales por medio de leyes que protegen la propiedad intelectual (en este caso: patentes).

Es así que algunas de estas propuestas críticas involucran el hecho de que los generadores de trabajo inmaterial no lo crean de su propio intelecto, sino que para que puedan desarrollar sus productos intelectuales necesitan de una carga de conocimiento social y colectivo que le ayudó a llegar al punto de creación y modificación de la realidad. Es de esta manera que se presenta una disputa entre las perspectivas univocistas presentes en una ley positiva y unas equivocistas relativas a un sin número de manifestaciones colectivas en contra del entendimiento hegemónico de la propiedad intelectual como un derecho humano.

\section{HERMENÉUTICA ANALÓGICA PARA LA MEDIACIÓN ENTRE LA PROPIEDAD INTELECTUAL Y} EL PROCOMÚN

La propuesta es el uso de la hermenéutica analógica para realizar de manera sucinta una mediación entre lo que sería las propuestas objetivas y las subjetivas en torno a la propiedad del conocimiento. Para ello es necesario mantenerse cerca de la propuesta univocista para no perder la objetividad tan importante al mencionarse en los derechos humanos. El principio que tendría que regir en este ejercicio analógico sería la libertad, así como el beneficio en común de la utilización de los productos culturales de la ciencia y la tecnología. De igual manera, se atiende los elementos de la prudencia y la equidad para lograr una estabilidad mínima que permita la convivencia entre ambas interpretaciones del derecho.

En este sentido, y atendiendo a la equidad se necesita establecer una base en que ambas propuestas se mantengan con la posibilidad de un beneficio económico que le permita subsistir de una manera adecuada a la persona que sean generadoras de la creación cultural. Es así que el principio de regulación se mantiene desde la propuesta objetiva. Así, pues, el diálogo aclara que no se está en contra de las producciones intelectuales ni las industriales, sino lo que buscan las propuestas subjetivistas a través de su crítica es la no-aceptación de un enriquecimiento sin sentido por parte de los creadores, y mucho menos de empresas particulares que se apropian del producto del trabajo. En otras palabras, se acepta que el desarrollo de este tipo de trabajo tenga una remuneración, pero no se acepta que se proteja de una manera absoluta sin una consideración de la colectividad y además se sancione de forma exorbitante a las personas que no cumplan con el texto de la ley. ${ }^{38}$

Es de esta manera que las interpretaciones llegan a una conciliación, y no a una síntesis, en la que se realza la diferencia, pero se mantiene un principio regulador objetivo. En esta lógica, se acepta un uso y un disfrute de los beneficios de la generación de los productos culturales, así como de la ciencia y la tecnología. Lo que se critica en este sentido es que el beneficio se encuentre mediado por una cantidad monetaria excesiva debido a la existencia de intermediarios protegidos por los derechos de la propiedad intelectual. Estas figuras jurídicas protectoras de las empresas y entes privados que posibilitan que exista un enriqueci-

\footnotetext{
${ }^{38}$ Tal es el caso de Aaron Swartz en Estados Unidos que fue acusado a 50 años de prisión y una multa de 4 millones de dólares por descargar y compartir en la red documentos del Instituto Tecnológico de Massachusetts (MIT) que se encontraban protegidos por derechos de propiedad intelectual. O el caso de Diego Gómez en Colombia que fue acusado de plagio por compartir una tesis en la conocida pagina de Scribd por lo cual enfrenta una pena de 8 años de prisión.
} 
miento por medio de la apropiación del trabajo de los/as productoras de mercancías bajo la lógica de mercado.

Atendiendo a la finalidad de los derechos humanos y tomando como punto de partida el uso alternativo del derecho se puede hacer un uso conveniente de la hermenéutica analógica estableciendo ese equilibrio que se necesita en el beneficio común y colectivo del conocimiento. Entonces, se concluye que aunque se mantenga un visión objetiva del derecho de la propiedad intelectual no es del todo legitimado como un derecho humano ya que involucra lógicas de acumulación de capital que son completamente cuestionables desde un horizonte crítico. Para ello es necesario ampliar el horizonte teórico más allá del derecho, es decir, permitir un análisis interdisciplinario en que se incluya otras ciencias en busca de la situación justa para las mayorías populares y no solamente para un grupo privilegiado. Así, manteniendo la equidad de las partes que se involucran en la disputa del conocimiento es indispensable hacer una controversia mucho más profunda y desestabilizadora de la realidad hegemónica y no sólo intentar una simple conciliación sin crítica de las lógicas que mantienen las interpretaciones universalistas.

\section{CONCLUSIONES}

La hermenéutica es un ciencia indispensable para dar un entendimiento de la realidad. $\mathrm{Al}$ existir un sin número de percepciones sobre una diversidad de temas esta herramienta resulta de gran utilidad para dar un sentido lógico al sin fin de posibilidades. No obstante, la hermenéutica analógica trae consigo una propuesta novedosa para generar un orden a las muchas interpretaciones posibles. La alternativa de diálogo establece una forma de análisis de lo sustancial a partir de los entendimientos generales o particulares que coexisten, aun sin estar dentro de una aceptación oficial.

En lo que respecta a su uso dentro del derecho y en los derechos humanos es pertinente su utilización. Sin embargo, necesita de actuar con otras formas de crítica que permita identificar y construir alternativas en el caso de encontrarse con un sistema de legitimación. Tal es el caso de las interpretaciones univocistas ya que al mantenerse ligadas a la perspectiva dominante han creado todo un modelo de protección bajo el cual se necesita más que una visibilización de diferencia. Es así, que la hermenéutica analógica en primer momento establecer una armonía, pero que posiblemente necesita de un elemento coercible que ayuda a modificar de una manera mucho más integral las situaciones de desigualdad que propician las interpretaciones universales. Asimismo, más allá de tener como objetivo una estabilidad o una positivización de las circunstancias diversas, es indispensable realizar una crítica a las lógicas que se visibilizan a través de los elementos, como la equidad o la prudencia, que utiliza la analogía.

Finalmente, aunque atendiendo a lo anteriormente mencionado, el uso de la hermenéutica analógica en el caso de los derechos de la propiedad intelectual frente al procomún evidencian la existencia de un régimen de interés económico que reta a la percepción del derecho. Es decir, para ampliar las posibilidades de dinámicas justas a través de este tipo de hermenéutica en el uso del conocimiento se requiere ampliar la perspectiva de análisis de la realidad. Por ello se propone dejar de lado la división tajante y moderna entre las ciencias para obtener panoramas interdisciplinarios que permitan el dialogo entre las posturas univocistas y universalizantes con aquellas relativas y subjetivas. En consecuencia, se espera 
atender a las demandas de los movimientos sociales que claman exigencias de sus realidades negadas para evidenciar las situaciones negadoras de sus derechos humanos.

Así, se evidencia una realidad que limita el acceso al conocimiento, y a los derechos humanos relacionados con el ejercicio de este derecho, a través de los derechos de la propiedad intelectual que si bien en primer momento intenta proteger los derechos de los/as creadores/ as termina por legitimar y ser parte de una dinámica global de acumulación de riqueza a costa del despojo de las mayorías. En fin, el uso de la hermenéutica analógica en este tema específico propicia la visibilidad de las exigencias de los diversos movimientos en un dialogo con la necesidad de un reconocimiento de las personas que emplean su trabajo en busca en bien general. Aunque, no es posible soslayar la necesidad de emancipar el intercambio de conocimientos de aquellos intermediarios que solamente buscan una apropiación del trabajo objetivado en el conocimiento producido para la sociedad.

FUENTES

\section{BIBLIOGRÁFICAS}

ÁVILA, Humberto, "Propuesta de disociación entre los principios y reglas", Teoría de los principios, Madrid, Marcial Pons, 2011.

BUGANZA TORIO, Jacobo, “Consideraciones sobre la hermenéutica analógica de Mauricio Beuchot”, Hermenéutica analógica, derecho y filosofía, San Luis Potosí, UASLP, 2007, pp. 9-30.

BEUCHOT, Mauricio, Hermenéutica analógica, analogía y derechos humanos, San Luis Potosí, CEJSM/UASLP, 2010.

, Mauricio, "Hermenéutica y Analogía. Exposición de la Hermenéutica Analógica”, La Hermenéutica como herramienta de la investigación social, San Luis Potosí, CEDH-USLP, 2007, pp. 9-19.

, Mauricio, "Hermenéutica analógica, derechos humanos y culturas", Problemas contemporáneos de la filosofía del derecho, México, UNAM, 2005, pp. 55-66.

, Mauricio, “El Estado de la cuestión: la hermenéutica”, en Diálogo Filosófico, núm. 61, México, 2005, pp. 4-28.

, Mauricio y Javier Saldaña, Derechos Humanos y naturaleza humana, UNAM, México, 2000.

BUSANICHE, Beatriz, "Conceptos clave para comprender la problemática”, Libres de monopolios sobre el conocimiento y la vida, San José Costa Rica,Vía Libre-Fundación Heinrich Boll, 2007, pp. 43-47.

CALVO, Manuel, "La voluntad del legislador: genealogía de una ficción hermenéutica" en Doxa Cuadernos de Filosofía del Derecho, núm. 3, México, Universidad de Alicante, pp $113-127$.

DE LA TORRE RANGEL, Jesús Antonio. El derecho como arma de liberación en América Latina: sociología y uso alternativo del derecho, San Luis Potosí, CENEJUS/UASLP, 2006. 
ELLACURÍA, Ignacio, "Historización de los derechos humanos desde los pueblos oprimidos y las mayorías populares", en Juan Antonio Senent (ed.) La lucha por la justicia. Selección de textos de Ignacio Ellacuría 1969-1989, Bilbao, Universidad de Deusto, 2012, pp. 365-376.

GADAMER, H. Georg, Fundamentos de una hermenéutica: verdad y método, Ana Agud Aparicio y Rafael de Agapito (Trads.), Salamanca, SIGUEME, 1993.

LESSIG, Lawrence, El código 2.o, Madrid, Traficante de sueños, 2009.

LLINARES, M., Fernando, "El futuro de la propiedad intelectual desde su pasado: historia de los derechos de autor y su porvenir ante la revolución del internet", en Revista de la Facultad de Ciencias Sociales y Jurídicas de Elche, Elche, Vol. I, núm. 2, 2007, pp. 103-155.

NAVARRETE, A., Lillian, Derecho de ¿autor?: el debate de hoy, Instituto Cubano del Libro, La Habana, 2006.

RENDULES, César, “Copiar, robar, mandar”, Revista Archipiélago, núm. 55, 2003, pp. 43-51.

ROJAS, Víctor. "La diferencia entre reglas y principios en Dworkin" en Ronald Dworkin y los principios generales del derecho, México, Porrúa, 2007, pp. 235-284.

STALLMAN, Richard M., Software libre para una sociedad libre, Jaron Rowan, Diego Sanz Paratcha y Laura Trinidad (trads.), Traficante de Sueños, Madrid, 2004.

TRUJILLO, Isabel. "El poder de la razón jurídica: nota sobre el desarrollo de la hermenéutica jurídica italiana”, en Cuadernos de filosofía del derecho, Doxa, núm. 27, 2004, pp. 437-453. [edición digital]

UNESCO. La propiedad intelectual como derecho de autor, UNESCO, núm. 3, 2001. [versión electrónica]

UNESCO, Boletín de derechos de autor, UNESCO, núm. 3, 1992. [versión electrónica]. 